\section{HUMANASE SOCIAIS \\ V.8・N.2 • Agosto/Setembro/Outubro - 2019 \\ ISSN Digital: 2316-3801 \\ ISSN Impresso: 2316-3348}

DOI: 10.17564/2316-3801.2019v8n2p113-128
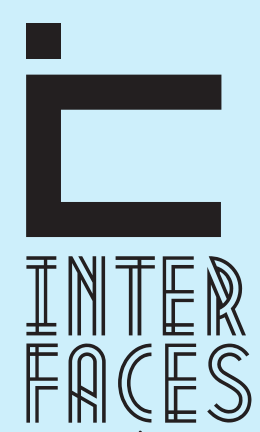

CIENTÍFICAS

\title{
A TRANSFOMAÇ̃̃O DA CONSCIÊNCIA DA DIGNIDADE HUMANA A PARTIR DA SEGUNDA GUERRA MUNDIAL
}

THE TRANSFORMATION OF THE CONSCIOUSNESS OF HUMAN DIGNITY FROM THE SECOND WORLD WAR

UNA TRANSFORMACIÓN DE LA CONCIENCIA DE LA DIGNIDAD HUMANA UN PARTIDODE LA SEGUNDA GUERRA MUNDIAL

Samyle Regina Matos Oliveira ${ }^{1}$ Verônica Teixeira Marques ${ }^{2}$

Gilvan Rodrigues dos Santos ${ }^{3}$

\section{RESUMO}

O objetivo do presente trabalho é demonstrar o quanto os horrores da Segunda Grande Guerra Mundial despertaram a transformação da consciência dos povos sobre a urgente necessidade de estabelecer princípios legais que pudessem, não apenas afastar os perigos iminentes de futuras guerras, mas também e fundamentalmente, proteger as exigências intrínsecas aos valores invioláveis da própria dignidade humana. Fruto de circunstâncias bélicas fratricidas, que tingem de sangue o manto histórico das civilizações, os tempos modernos sinalizam que não deveria mais haver espaços para a barbárie, com graves e danosas consequências para a degradação da dignidade humana. Então, no contexto do pós-guerra, surgiram muitos institutos internacionais com o sublime intuito de proteger os povos coletivamente, mediante as relações internacionais, e os indivíduos singularmente, por meio da convivência social. A Carta das Nações Unidas, de 1945, e a Declaração Universal dos Direitos Humanos, de 1948, ao lado de tantas outras Convenções Internacionais - Convenção de Viena sobre o Direito dos Tratados (CVDT), Convenção Americana sobre Direitos Humanos (Pacto de São José da Costa Rica), entre outros organismos, inclusive de julgamento, como o Tribunal de Nuremberg e o Tribunal de Haia - são protótipos inescusáveis desse esforço coletivo internacional. Mesmo assim, não obstante todo o esforço da Liga das Nações e da própria ONU diante dos desafios para apaziguar os conflitos em alguns países, ainda há uma grande distância da paz mundial tão sonhada e desejada.

\section{PALAVRAS-CHAVE}

Convenções Internacionais. Dignidade Humana. Direitos Humanos. Guerra 


\section{ABSTRACT}

The purpose of this summary is to demonstrate in a technical and scientific way how the nightmares of the Second World War caused the transformation of peoples' conscience on the urgent need to establish legal principles that could not only ward off the imminent dangers of future wars, but also and fundamentally, to protect the requirements intrinsic to the inviolable values of human dignity itself. As a result of fratricidal warlike circumstances, which taint the historical cloak of civilization with blood, modern times indicate that there should be no more space for barbarism, with grave and damaging consequences for the degradation of human dignity. Then, in the post-war context, many international institutes emerged with the sublime intention of protecting peoples collectively, through international relations, and individuals singularly through social coexistence. The United Nations Charter of 1945 and the Universal Declaration of Human Rights of 1948, alongside so many other International Conventions - the Vienna Convention on the Law of Treaties (CVDT), the American Convention on Human Rights (Pact of St. Joseph of Costa Rica), among other bodies, including the trial court, such as the Nuremberg Tribunal and the Hague Tribunal - are inexcusable prototypes of this international collective effort. Even so, we can conclude that, despite everything, the failure of the League of Nations and the UN itself, faced with the challenges to appease the conflicts in some countries, we are still far from the dreamed and desired peace.

\section{KEYWORDS}

Human dignity. Human Rights. International Conventions. War.

\section{RESUMEN}

El objetivo del presente trabajo es demostrar cuánto los horrores de la Segunda Gran Guerra Mundial despertaron la transformación de la conciencia de los pueblos sobre la urgente necesidad de establecer principios legales que pudieran, no sólo apartar los peligros inminentes de futuras guerras, sino también y fundamentalmente, proteger las exigencias intrínsecas a los valores inviolables de la propia dignidad humana. Fruto de circunstancias bélicas fratricidas, que teñen de sangre el manto histórico de las civilizaciones, los tiempos modernos señalan que ya no debería haber espacios para la barbarie, con graves y dañosas consecuencias para la degradación de la dignidad humana. Entonces, en el contexto de la posguerra, surgieron muchos institutos internacionales con el sublime propósito de proteger a los pueblos colectivamente, mediante las relaciones internacionales, y los individuos singularmente, por medio de la convivencia social. La Carta de las Naciones Unidas, de 1945, y la Declaración Universal de los Derechos Humanos, de 1948, junto a tantas otras Convencio- 
nes Internacionales - Convención de Viena sobre el Derecho de los Tratados (CVDT), Convención Americana sobre Derechos Humanos (Pacto de San José de Costa Rica), entre otros organismos, incluso de juicio, como el Tribunal de Nuremberg y el Tribunal de La Haya - son prototipos ineludibles de ese esfuerzo colectivo internacional. Sin embargo, a pesar de todo el esfuerzo de la Liga de las Naciones y de la propia ONU ante los desafíos para apaciguar los conflictos en algunos países, todavía hay una gran distancia de la paz mundial tan soñada y deseada.

\section{PALABRAS CLAVE}

Convenciones Internacionales. Dignidad Humana. Derechos humanos. Guerra

\section{INTRODUÇ̧̃̃o}

Não por acaso, o homem é o lobo do homem - homo homini lupus - um pensamento clássico do latim, atribuído ao pensador Plauto em sua obra Asinaria, do século III a. C., considerada um dos mais antigos textos latinos. Bem mais tarde, já no século XVII, o filósofo inglês Thomas Hobbes tornou notório o rifão. E, assim, se arrasta a história da humanidade que sempre se debateu nas incongruências da convivência pacífica entre os iguais. Diante disso, o presente trabalho, desenvolvido por meio do método de revisão bibliográfica, tem por objetivo demonstrar que a Segunda Guerra Mundial foi uma marca que ensejou o despertar da consciência dos homens para o enfoque da dignidade humana e suas exigências. Portanto, dentro desse contexto, como os institutos internacionais poderiam refrear ou conter $\mathrm{o}$ avanço das arbitrariedades que aviltam os direitos inerentes à dignidade humana?

No sentido de buscar responder a tal questionamento, foi realizada uma pesquisa bibliográfica com base em vários autores que ajudaram a construir, de modo categórico, a dimensão teleológica da proposição inicial. Destarte, o primeiro capítulo aborda a maneira como a Segunda Guerra Mundial favoreceu a explosão da consciência dos povos quanto à urgência dignidade humana. Assim, a beligerância dos conflitos que sempre perturbaram a paz mundial atingiu o acinte de gravidade na reflexão suscitada pelo Pós-Guerra. Noutro momento, com o segundo capítulo, a dinâmica do texto segue o fluxo pensante de abordagens que confluem para o fato de que, subsequentemente aos horrores e vilipêndios da dignidade humana, recrudescidos com o advento da Segunda Guerra, instigou-se mais o apelo internacional dos povos à importância em salvaguardar as reivindicações da dignidade humana. Portanto, foi à mercê dessa contingência comportamental, que surgiram os institutos internacionais protetivos da dignidade humana. Depois, já no terceiro capítulo, foram apontados também ulteriores vestígios de quanto o pós-guerra produziu o florescimento da insistência relativa à possibilidade de, sobretudo, as constituições dos países adotarem a riqueza do que foi sendo construído ao longo dos séculos em relação ao tema, e que, agora, ganha maior relevo e projeção na geopolítica mundial pelo abraço da internacionalidade contemporânea. 
Sendo assim, não obstante todo o esforço na superação das desigualdades sociais, políticas, culturais e econômicas, entre outras patrocinadas pelos organismos internacionais de proteção e aquiescência aos direitos da dignidade humana, ainda há muito por fazer em âmbito internacional mais amplo. Infelizmente, a sutileza com que a violência continua destruindo milhões de vidas em muitos lugares da terra, inclusive no Brasil, onde a linha tênue da barbárie se esconde na macrogeografia do país, deve ser uma preocupação de todas as nações.

\section{A SEGUNDA GUERRA MUNDIAL E A EXPLOSÃO DA CONSCIÊNCIA DA DIGNIDADE HUMANA}

A guerra por si mesma não é uma novidade dos tempos modernos, pois as hostilidades antropológicas estão presentes no seio das sociedades que compõem a esteira civilizatória do horizonte dos povos. No entanto, com o avanço científico e tecnológico no âmbito do conhecimento, inclusive beligerante, cresceram também as possiblidades de batalhas cruentas e arrojadas, de fácil calibre ou dimensão universal, atingindo nações mais distantes, com alcance geográfico mais imediato. E o pior, com câmaras televisivas e aparelhos modernos de sofisticada tecnologia, publica-se, ao vivo, o sangue derramado em cada esquina do mundo. Mesmo assim, a humanidade não havia experimentado o rigor da estupidez em proporções tão gigantescas da bestialidade humana como quando das duas Grandes Guerras Mundiais que flagelaram e torturaram a humanidade inteira. Todavia, será o enfoque da Segunda Guerra Mundial - e a partir dela - o que conduzirá a consciência humana sob a luz esperançosa do resgate da dignidade humana.

A Segunda Grande Guerra Mundial, pelos horrores cometidos, sobretudo pelo nazismo, mexeu muito com o psicológico e a consciência dos povos envolvidos diretamente, ou não, nos dramas bélicos que vitimaram centenas de milhares de vidas humanas, entre homens, mulheres, jovens, velhos e crianças. A Segunda Guerra sacudiu o pó das consciências, despertando-as para o socorro humanitário com o aparecimento das instituições jurídicas internacionais de proteção à dignidade de todo ser humano em qualquer parte do mundo. E, então surgiram a Liga das Nações e, algum tempo depois, a Organização das Nações Unidas, com a Declaração Universal dos Direitos Humanos, entre outros tratados, e convenções, e pactos que também serão objeto de estudo nesse trabalho, especialmente orientado, com o auxílio de muitos autores, para a construção da necessidade do amadurecimento das exigências da consciência da dignidade humana e de suas inelutáveis obrigações no cenário internacional contemporâneo.

Esse marco histórico no panorama "anticivilizatório" da humanidade foi também uma oportunidade irreversível na consciência dos povos, no sentido da transformação radical na concepção profunda quanto às exigências da dignidade humana. Na verdade, o advento da Segunda Guerra Mundial despertou as consciências para um momento novo, com plena floração na perspectiva axiológica dos direitos fundamentais da pessoa humana. Com efeito, "considerando a historicidade dos direitos destaca-se a chamada concepção contemporânea dos direitos humanos, que veio a ser introduzida pela Declaração Universal de 1948 e reiterada pela Declaração de Direitos Humanas de Viena de 
1993". (PIOVESAN, 2017, p. 50). Nesse contexto, direitos humanos estão obrigatoriamente ajustados à dignidade do ser pessoa. Jures propii hominum, isto é, os direitos são próprios dos homens, no sentido lato da palavra, quer dizer, de todos os seres humanos.

Segundo Zippelius (2016, p. 504), “a grande divisa da Revolução francesa liberté, égalité, fraternité, continua a constituir o conceito central do entendimento dos direitos fundamentais. Ainda hoje, os direitos fundamentais se classificam em 'direitos de liberdade' e 'direitos de igualdade”. E ele continua: "Foi só nos nossos tempos, que a fraternité alcançou pleno desenvolvimento sob as signações de 'Estado social' ou 'solidariedade”'. (ZIPPELIUS, 2016, p. 504).

Num breve aceno e esforço de compreensão do termo "dignidade da pessoa humana", especialmente no contexto do "direito constitucional contemporâneo", Christopher McCrudden (2008, apud BARROSO, 2014, p. 13) afirma que, no âmbito da origem e evolução, pode-se reconhecer que “Em uma linha de desenvolvimento que remonta a Roma antiga, atravessa a Idade Média e chega até o surgimento do Estado liberal, a dignidade - dignitas - era um conceito associado ao status pessoal de alguns indivíduos ou à proeminência de determinadas instituições”. No mesmo texto, destaca-se ainda que, até o século XVIII, não havia nenhuma relação entre a dignidade e os direitos humanos, enfatizando que, "na Declaração Universal dos Direito do Homem e do Cidadão de 1789, ela estava entrelaçada com ocupações e posições públicas”. (BARROSO, 2014, p. 13-14). Em outras palavras, "nos Estados Unidos, as referências à dignidade humana nos Artigos Federalistas, por exemplo, diziam respeito a cargos, ao governo ou a nação como um todo”. (BARROSO, 2014, p. 14). Mais adiante, Borroso (2014, pp. 14-15) acrescenta:

A dignidade humana, como atualmente compreendida, se assenta sobre o pressuposto de que cada ser humano possui um valor intrínseco e desfruta de uma posição especial no universo. Diversas religiões, teologias e concepções filosóficas buscam justificar essa visão metafísica. O longo desenvolvimento da compreensão contemporânea de dignidade humana se iniciou com o pensamento clássico e tem como marcos a tradição judaico-cristã, o lluminismo e o período imediatamente posterior ao fim da Segunda Guerra Mundial.

Deixando de lado outras considerações sobre as origens da "dignidade humana", como por exemplo, a influência filosófica clássica do helenismo, os textos do Antigo 4 e do Novo Testamento, com incidência particular do Cristianismo, e, por isso mesmo, também a avassaladora interferência religiosa, deve-se considerar que o texto supracitado confirma a tese de que, evidentemente, o pós-segunda Guerra Mundial foi uma referência importantíssima para a iluminação da consciência da dignidade humana. Com efeito,

\footnotetext{
4 "A justificativa religiosa da preeminência do ser humano surgiu com a afirmação da fé monoteísta. A grande contribuição do povo da Bíblia à Humanidade, uma das maiores, aliás, de toda a História, foi a ideia da criação do mundo por um Deus único e transcendente. Os deuses antigos, de certa forma, faziam parte do mundo, como super-homens, com as mesmas paixões e defeitos do ser humano. lahweh [o Senhor], muito ao contrário, como criador de tudo o que existe, é anterior ao mundo". (Comparato, 2015, p. 15).
} 
Ao lado dos marcos religiosos e filosóficos já identificados, existe o marco histórico significativo, que foi decisivo para o delineamento da noção atual de dignidade humana: os horrores do nacional-socialismo e do fascismo, e a reação que eles provocaram no após o fim da Segunda Guerra Mundial. Na reconstrução de um mundo moralmente devastado pelo totalitarismo e pelo genocídio, a dignidade humana foi incorporada ao discurso político dos vitoriosos como uma das bases para uma longamente aguardada era de paz, democracia e proteção dos direitos humanos. (BARROSO, 2014, pp. 18-19).

O texto de Barroso (2014), na sua inteireza, pode dar uma compreensão bem mais ampla a quem desejar aprofundar o conteúdo, especialmente do ponto de vista histórico, a partir de seu próprio título: "A dignidade da pessoa humana no direito constitucional contemporâneo - A Construção de um Conceito Jurídico à Luz da Jurisprudência Mundial”. Nesse sentido, ainda assevera:

Em um primeiro momento, a proteção e promoção da dignidade humana foram consideradas tarefas exclusivas dos poderes políticos do Estado, ou seja, dos poderes do Executivo e Legislativo. Não demorou muito, entretanto, para que essas metas políticas e valores morais inscritos na dignidade migrassem para o direito. Uma razão óbvia para essa migração foi o fato de a dignidade humana ter sido consagrada em diversos documentos e tratados internacionais, assim como em muitas constituições nacionais. Mas essa ascensão da dignidade humana como um conceito jurídico, nos dois lados do Atlântico, foi consequência de uma mudança fundamental no pensamento jurídico, que se tornou mais visível e concreta depois da Segunda Guerra. (BARROSO, 2014, p. 62).

Ou seja, mais uma vez, Barroso (2014) corrobora com a ideia da contribuição da Segunda Guerra para o surgimento de uma consciência mundial pautada na dignidade humana. 0 autor, com muita competência científica e epistemológica, aborda outros aspectos relacionados à dignidade humana como, por exemplo, se ela é absoluta ou não, isto é, se se trata de um "valor absoluto, que prevalece em qualquer circunstância” (BARROSO, 2014, p. 64); se ela é limitada diante das próprias vicissitudes fáticas que, de algum modo, condicionam os ditames da jurisprudência, e assim por diante. Ele é muito enfático e incisivo, quando diz: "Coerente com a posição aqui sustentada de que a dignidade humana não é o valor absoluto é a afirmação de que ela tampouco é um princípio absoluto. De fato, se um princípio constitucional pode estar por trás tanto de um direito fundamental quanto de uma meta coletiva, e se seus direitos colidem entre si e com as metas coletivas, um impasse lógico ocorreria”. (BARROSO, 2014, p. 66). Todavia, não é o caso dessa reflexão aqui.

De acordo com Piovesan (2017) é possível verificar avanços já realizados desde a Segunda Guerra Mundial, na direção do respeito individual e coletivo, mas, sobretudo dos Estados constituídos, quanto aos direitos intrínsecos à dignidade humana. Hoje, com a multifacetada percepção do complexo universo que se expande com a proeminência concernente às diferenças emergidas das liberdades conclamadas por todos, tais exigências de respeito e tolerâncias à dignidade humana são mais evidenciadas e, por conseguinte, mais contundentes. Trata-se, pois, de aceitar 
que a abertura ao diálogo entre as culturas, com respeito à diversidade e com base no reconhecimento do outro, como ser pleno de dignidade e direitos, é condição para a celebração de uma cultura de direitos humanos, inspirada pela observância do 'mínimo ético irredutível', alcançado por um universalismo de confluência”. (PIOVESAN, 2017, pp. 61-62).

Recorrendo ao pensamento de Joaquín Herrera Flores (apudPIOVESAN, 2017, p. 60), a autora destaca também a "necessidade de superar o debate sobre o universalismo e relativismo cultural, a partir da transformação cosmopolita dos direitos humanos". Na sua visão, isso favoreceria o anelado "diálogo intercultural" na perspectiva da tutela e da garantia da inelutável proteção dos direitos humanos que precisariam ser, cada vez mais, bem internacionalizados. Segundo Piovesan (2017, p. 61-62), essa “internacionalização dos direitos humanos constitui um movimento extremamente recente na história, surgindo, a partir do Pós-Guerra, como resposta às atrocidades e aos horrores cometidos durante o nazismo".

Portanto, na concepção de Piovesan (2017, p. 51), "A barbárie do totalitarismo significou a ruptura do paradigma dos direitos humanos, por meio da negação do valor da pessoa humana como valor-fonte do Direito. Se a Segunda Guerra significou a ruptura com os direitos humanos, o Pós-guerra deveria significa a sua reconstrução". Desse modo, a chegada de tempos novos no contexto da abrangência internacional dos direitos relativos à dignidade humana sinalizava também o sentido de novas esperanças.

\section{INSTITUTOS INTERNACIONAIS DE DEFESA DA DIGNIDADE HUMANA}

A proteção internacional do princípio da dignidade da pessoa humana surge do desenvolvimento de uma consciência internacional (BARROSO, 2014, pp. 19-20). Ou seja:

Apesar de sua relativa proeminência na história das ideias, foi apenas ao final da segunda década do século XX que a dignidade humana começou a aparecer nos documentos jurídicos, começando com a Constituição do México (1917) e com a Constituição alemã da República de Weimar (1919). Antes de alcançar seu apogeu como símbolo humanista, a dignidade esteve presente em escritos de natureza menos democrática, tais como o esboço de constituição do marechal Petain (1940), na França, elaborado durante o período de colaboração com os nazistas, e a Lei Constitucional decretada por Francisco Franco (1945), durante a longa ditadura espanhola. Depois da Segunda Guerra Mundial, a dignidade foi incorporada a importantes documentos internacionais, como a Carta das Nações Unidas (1945), a Declaração Universal dos Direitos Humanos (1948) e outros numerosos tratados e pactos que exercem um papel central nos debates atuais sobre direitos humanos. Mais recentemente, a dignidade recebeu atenção especial na Carta Europeia de Direitos Fundamentais (2000) e no esboço da Constituição Europeia (2004).

Sem dúvida, a amplitude de referências à dignidade humana em todos esses documentos, como igualmente em muitas Constituições de vários países, demonstra a importância dessa concepção 
suscitada pela sociedade contemporânea, sobretudo, no conjunto das proximidades favorecidas pela globalização. Com efeito, para David Sánchez Rubio (apud Pagliarini in Bertoldi; Sposato, 2011, p. 59), a conformação de um mundo global provocou a consciência de um destino comum para toda a humanidade. A globalização e seus diversos processos possibilitaram espaços de interconexões entre as pessoas pertencentes a diversos pontos da Terra. Por conseguinte, na visão de Comparato (2015, p. 82), tem-se início à "era da cidadania mundial”. Isso quer dizer que, por cima das fronteiras que tentam separar os limites da dignidade humana, sobretudo em países fechados e isolados do resto do mundo pela "cortina de ferro" de ditaturas impermeáveis, levanta-se o estandarte da igualdade de todos os povos e de cada indivíduo, reivindicando o respeito e o dever à proteção de sua dignidade humana. Portanto, dentro dessas conjunturas hodiernas,

Ao emergir da Segunda Guerra Mundial, após três lustros de massacres e atrocidades de toda sorte, iniciados com o fortalecimento do totalitarismo estatal dos anos 30 , a humanidade compreendeu, mais do que em qualquer outra época da História, o valor supremo da dignidade humana. 0 sofrimento como matriz da compreensão do mundo e dos homens, segundo a lição luminosa da sabedoria grega, veio aprofundar a afirmação histórica dos direitos humanos. (COMPARATO, 2015, pp. 68-69).

Comparato (2015, p. 69) afirma ainda que, ao lado dos "direitos individuais, de natureza civil e política, ou os direitos de conteúdo econômico e social", que foram "assentados no plano internacional”, afirmou-se "também a existência de novas espécies de direitos humanos: direitos dos povos e direitos da humanidade". Nesse contexto, a introdução do preâmbulo da Carta das Nações Unidas (in ANGHER, 2017, p. 1971), assinada em São Francisco, na Califórnia, entrada em vigor no dia 24 de outubro de 1945, é muito significativo:

NÓS, OS POVOS DAS NAÇÕES UNIDAS, RESOLVIDOS a preservar as gerações vindouras do flagelo da guerra, que por duas vezes, no espaço de nossa vida, trouxe sofrimentos indizíveis à humanidade, e a reafirmar a fé nos direitos fundamentais do homem, na dignidade e no valor do ser humano, na igualdade de direito dos homens e das mulheres, assim como das nações grandes e pequenas, e a estabelecer condições sob as quais a justiça e o respeito às obrigações decorrentes de tratados e de outras fontes do direito internacional possam ser mantidos, e a promover o progresso social e melhores condições de vida dentro de uma liberdade ampla.

Na verdade, o texto acima referido nada mais é do que uma síntese programática de todo o conteúdo da Carta que, ao largo de seus 111 artigos, aborda a urgência com que todas as nações envolvidas na assinatura, enquanto signatárias do projeto nela contido, devem se comprometer segundo os propósitos ali estatuídos como norma a ser cumprida. Destarte, entre os propósitose princípios do art. 1, encontra-se:

Manter a paz e a segurança internacionais e, para esse fim: tomar, coletivamente, medidas efetivas para evitar ameaças à paz e reprimir os atos de agressão ou outra qualquer

Interfaces Científicas Humanas e Sociais • Aracaju • V.8 • N.2 • p. 113 - 128 • Agosto/Setembro/Outubro - 2019 
ruptura da paz e chegar, por meios pacíficos e de conformidade com os princípios da justiça e do direito internacional, a um ajuste ou solução das controvérsias ou situações que possam levar a uma perturbação da paz; (in ANGHER, 2017, p. 1971).

Ao embalo dos bons presságios que se seguiram à publicação da Carta das Nações Unidas, a Declaração Universal dos Direitos Humanos, aprovada apela Resolução nº. 217, durante a $3^{a}$. Assembleia-Geral da ONU, em Paris, na França, em 10 de dezembro de 1948, foi outro acontecimento importantíssimo, a fim de corroborar e consolidar ainda mais os fundamentos axiológicos pressupostos na Carta das Nações Unidas, poucos anos antes. Agora, com mais ênfase e destaque no reconhecimento da amplitude integral da dignidade humana, outros aspectos foram considerados para enriquecer a totalidade da concepção do ser pessoa, tanto na sua singularidade quanto na conjuntura da coletividade social. Assim, pois, aquela Assembleia-Geral da ONU proclamou:

A presente Declaração dos Direitos Humanos como o ideal comum a ser atingido por todos os povos e todas as nações, com o objetivo de que cada indivíduo e cada órgão da sociedade, tendo sempre em mente esta Declaração, se esforce, através do ensino e da educação, por promover o respeito a esses direitos e liberdades, e, pela adoção de medidas progressivas de caráter nacional e internacional, por assegurar o seu reconhecimento e a sua observância universais e efetivos, tanto entre os povos dos próprios Estados-Membros, quanto entre os povos dos territórios sob sua jurisdição. (in ANGHER, 2017, p. 1982).

É o critério da fraternidade universal que acoberta a dignidade de todos os povos e de todas as pessoas, considerando, pois, que o "reconhecimento da dignidade inerente a todos os membros da família humana, e de seus direitos iguais e inalienáveis é o fundamento da liberdade, da justiça e da paz no mundo" (in ANGHER, 2017, p. 1982). Além disso, ainda no artigo primeiro da mesma Declaração evidencia-se, na parte introdutória dos “considerando...", que "todas as pessoas nascem livres e iguais em dignidade e direitos. São dotadas de razão e consciência e devem agir em relação umas às outras com espírito de fraternidade”.

Talvez, as consequências trágicas do evento da Segunda Grande Guerra Mundial tenham despertado também a consciência dos homens para o alcance da aplicabilidade mais efetiva da vivência fraterna entre os povos, provocando, assim, uma autêntica "transformação cultural", segundo a afirmação de Clara Machado (2017, p. 157):

Certo é que o princípio da fraternidade e a consequente proteção a direitos fundamentais transindividuais não dependem apenas da Constituição ou da Declaração dos Direitos humanos, que já cumpriram a função de trazer para o ordenamento jurídico interno e internacional o discurso da fraternidade, mas está acoplado a uma transformação cultural. [...] Como se demonstrou, a noção de fraternidade varia no tempo e no espaço e sofre o impacto da história e da cultura de cada povo, bem como de circunstâncias políticas, jurídicas e ideológicas. Inquestionavelmente, o princípio da fraternidade desperta a consciência de reconhecimento e de responsabilidade em relação ao "outro" e à comunidade. 
Com base na concepção do acima referido ao que concerne à "relação ao 'outro' e à comunidade", acobertado pelo véu da "fraternidade", infelizmente, o panorama geopolítico da comunidade dos povos ainda está distante da paz desejada. Isso significa dizer que a civilização ainda está com a consciência adormecida diante das tragédias humanitárias que grassam sobre nações em conflitos. Com efeito, o fenômeno psicológico da capacidade da consciência humana progredir em relação às necessidades da paz universal nas nações e entre as nações, avança a passos lentos e nem sempre consegue estabelecer a urgência demandada por si mesma na direção desse amadurecimento.

Indubitavelmente, a Constituição de Weimar, no início do século XX, já era um sopro positivo no sentido de inspirar e influenciar na

evolução das instituições políticas em todo o Ocidente. O Estado da democracia social, cujas linhas-mestras já haviam sido traçadas pela Constituição mexicana de 1917, adquiriu na Alemanha de 1919 uma estrutura mais elaborada, que veio a ser retomada em vários países após o trágico interregno nazifascista e a Segunda Guerra Mundial. A democracia social representou efetivamente, até o final do século XX, a melhor defesa da dignidade humana, ao comentar os direitos civis e políticos - que o sistema comunista negava - com os direitos econômicos e sociais, ignorados pelo liberal-capitalismo. (COMPARATO, 2015, p. 205).

Dentro desse contexto, Comparato (2015), entende uma dimensão mais ampla da dignidade humana, que envolve, além dos direitos individuais e coletivos, outros aspectos evidenciados, por exemplo, pelo Pacto Internacional dos Direitos Sociais, Econômicos e Culturais5, que entrou em vigor na ordem internacional em 1976, dez anos depois de ser "Adotado e aberto à assinatura, ratificação e adesão pela resolução 2200A (XXI) da Assembleia Geral das Nações Unidas”, isto é, em 1966. Trata-se de um texto simples, mas denso do ponto de vista da abordagem quanto aos direitos devidos à formação humana, direito à vida, à educação, à liberdade religiosa, especialmente, conforme enunciado no preâmbulo, no que concerne ao fato de que "o reconhecimento da dignidade inerente a todos os membros da família humana e dos seus direitos iguais e inalienáveis constitui o fundamento da liberdade, da justiça e da paz no Mundo". No art. $1^{\circ}$., n 1, o Pacto destaca que "todos os povos têm o direito de dispor deles mesmos. Em virtude deste direito, ele determinam livremente o seu estatuto político e asseguram livremente o seu desenvolvimento econômico, cultural e social”.

Portanto, de algum modo, o pensamento que costura o veio do nexo da preocupação com a paz entre os povos passa pela linha da educação integral da pessoa humana, não apenas no seio da família, que consoante o Pacto Internacional "é o núcleo elementar natural e fundamental da sociedade" (art. $10^{\circ}$., n. 1), mas também em tudo o que o Estado poderia patrocinar para aprimorar a riqueza da consciência da dignidade humana de todos os povos que compõem a grande família da humanidade inteira.

5 Disponível em http://www.unfpa.org.br/Arquivos/pacto_internacional.pdf, 1976, acessado em 9.05.2018. Tão importantes são também esses direitos que ele fazem parte da concepção da "universalidade" e "indivisibilidade" desses mesmos direitos. "Universalidade porque clama pela extensão universal dos direitos humanos [...]. Indivisibilidade porque a garantia dos direitos civis e políticos é condição para a observância dos direitos sociais, econômicos e culturais e vice-versa. Quando um deles é violado, os demais também o são". (PIOVESAN, 2017, p. 55). 


\section{OUTROS VISLUMBRES HISTÓRICOS DO PÓS-GUERRA}

É importante destacar também, além da Segunda Guerra, outros reflexos históricos ${ }^{6}$ que, de modo paulatino, também fizeram parte do processo de amadurecimento da consciência humana dos povos quanto à dignidade humana do pós-guerra.

Embora a humanidade já tivesse conhecido a lista dos direitos dos Estados Unidos da América - Bill of Rights, de 1791, escritos por James Madison, que por sinal, foram sucedidos pela Declaração de Direitos da Inglaterra, de 1689, que já propunha algum tipo de limites ao poder do monarca - chegara o momento de repensar os valores da dignidade humana sob novos prismas e matizes?. Então, a Alemanha adotou a Lei Fundamental de Bonn, promulgada no dia 23 de maio de 1949. E por ocasião do aniversário de 60 anos da referida Lei, na embaixada da Alemanha, foi proferido belo discurso que, entre outras reflexões destacava: "Esta Constituição é a pedra fundamental que não só fundou a República Federal da Alemanha, reconstruindo a democracia com absoluto sucesso, como também foi o sustentáculo da reunificação em 1990". A preleção, bastante fundamentada no ambiente jurídico de novas exigências mundiais para mudança de comportamento ético e moral em face dos acontecimentos da guerra, foi articulada por autor desconhecido, mas fazendo referência a Peter Häberle ${ }^{8}$, jurista tedesco, especialista em direito constitucional. No texto, foi enfatizada a importância de a alusiva constituição ter tido "grande influência no desenvolvimento da democracia em diversas Constituições no mundo todo".

Por sua vez, "no âmbito do Direito Constitucional ocidental, testemunha-se a elaboração de textos constitucionais abertos a princípios, dotados de elevada carga axiológica, com destaque ao valor da dignidade humana". (PIOVESAN, 2017, p. 53). No entanto, a Guerra Fria, entre os Estados Unidos e a Rússia ou a Antiga União Soviética, por exemplo, é o testemunho de que a

6 "A evolução e as vicissitudes dos direitos fundamentais, seja numa linha de alargamento e aprofundamento, seja numa linha de retração ou de obnubilação, acompanham o processo histórico, as lutas sociais e os contrastes de regimes políticos - bem como o processo científico, técnico e econômico (que permite satisfazer necessidades cada vez maiores de populações cada vez mais urbanizadas)". (Miranda in Bertoldi; Sposato, 2011, p. 89). Na percepção desse autor, "um papel extraordinariamente importante está reservado à história na verificação da variedade de condições de realização dos direitos da pessoa, dentro da unidade do gênero humano; no confronto de experiências, ora de sedimentação, ora de crise; e no descobrir de novos percursos e de novos avanços”. (Miranda in Bertoldi; Sposato, 2011, p. 99). De fato, a história é a mãe de todos os eventos que acobertam as transformações sociais tanto positivas quanto negativas, o que pode favorecer o amadurecimento da consciência dos povos quanto aos direitos de sua dignidade humana.

7 Nesse âmbito, parece-me legítimo considerar também a importância do relevante evento histórico da Revolução Francesa (1789), com a Declaração dos Direitos do Homem e do Cidadão, que, na visão de Bobbio (2004, p. 79), "representou um daqueles momentos decisivos, pelo menos simbolicamente, que assinalam o fim de uma época e o início de outra e, portanto, indicam uma virada na história do gênero humano". Para Alexis de Tocqueville (1805-1859) (apud Bobbio, 2004, p. 80), trata-se de "um tempo do qual, apesar de todos os erros, os homens iriam conservar eterna memória, e que, por muito tempo ainda, perturbará o sono dos que querem subjugar ou corromper os homens”. Com efeito, "foi a Revolução Francesa que constituiu, por mais de dois séculos, o modelo ideal para todos os que combateram pela própria emancipação e pela libertação do próprio povo". (Bobbio, 2004, p. 85).

8 Disponível em: http://www.stf.jus.br/arquivo/cms/noticiaArtigoDiscurso/anexo/discAlemanha.pdf, 2009, acessado em 28.03.2018.

Interfaces Científicas Humanas e Sociais• Aracaju • V.8 • N.2 • p. 113 - 128 - Agosto/Setembro/Outubro - 2019 
humanidade não parecia amadurecida, como se nenhuma lição tivesse aprendido com a Segunda Guerra Mundial. 0 mundo continuou dividido!

Na compreensão de Sato (2000) de Sato, outros aspectos são vislumbrados na elasticidade do século XIX e XX, como por exemplo, a mudança do contexto ideológico, a intenção do liberalismo como resposta ao problema da riqueza, do emprego e da renda, a situação do livre comércio, a crise dos anos 30, com a queda da bolsa de Nova York, a influência da Grã-Bretanha nas relações internacionais, o tema do meio ambiente, as próprias duas Grandes Guerras, a ampliação da noção de conflito em contextos globais, e até mesmo "a frustração produzida pela Liga das Nações [que] reforçava essas percepções acerca da natureza intrinsecamente conflitiva do meio internacional” (SATO, 2000), entre tantos outros fatos que, por causa da delimitação do tema, não poderiam ser aprofundados aqui, pois, do contrário, o corpo literário presente seria muito mais extenso, quase interminável, inconcludente.

\section{CONSIDERAÇÕES FINAIS}

Não obstante todo o esforço feito por organismos internacionais no sentido de tutelar e proteger os direitos intrínsecos à sublimidade da dignidade humana, ainda hoje, programas bélicos de supostos armamentos nucleares ou de armazenamento de armas químicas continuam gerando muita insegurança e ameaça à dignidade das pessoas.

As guerras sempre subsistirão, mais violentas ou não, tiranizando as pessoas e diminuindo, em vários níveis de degradação, as condições favoráveis à sobrevivência da dignidade humana. Com efeito, conflitos ainda se estendem em países fechados à comunidade internacional, sem a possibilidade de que observadores internacionais ou até mesmo a ONU possam auxiliá-los na superação das dificuldades internas, inclusive com ajuda humanitária. A democracia tem sido um esforço de muitas nações que não tem ajudado muito a reverter ou preposterar o quadro desafiador dos países emergentes, que lutam por independência. Blocos de Estados do leste europeu se desfizeram, como foi o caso da União Soviética de Mikhail Sergueievitch Gorbachev, mediante o processo de abertura política (Glasnost) e econômica (Perestroika), que, por sinal, pôs término à guerra Fria, e do esfacelamento da antiga lugoslávia, então constituída por seis repúblicas socialistas. Tudo isso, sem falar do conflito da Caxemira que ainda hoje perdura na batalha pela independência, brigando entre a Índia, a China e o Paquistão.

Ao lado disso tudo, é importante lembrar, ainda, a dificuldade da disfunção estatal brasileira em relação à guerra silenciosa que acontece no Brasil, onde, cotidianamente, vidas humanas são ceifadas pela brutalidade do tsunami da violência e do desrespeito aos princípios basilares da dignidade humana, e que ameaça também aqueles que ela não conseguiu matá-los ainda. Consoante dados estatísticos, nesse momento, nenhuma guerra no mundo contemporâneo mata mais do que se extermina vidas no Brasil. Então, partindo dessa constatação, será que o Brasil não precisaria de uma intervenção internacional por organismos da ONU, cobrando a imposição de limites a tanta barbaridade, a fim de refrear o arsenal bélico invisível que dizima a população do país? Tudo isso para indicar, conclusivamente, que 
a paz e a segurança internacionais tão desejadas entre os povos ainda permanece um sonho utópico utopia, do grego, significa "em lugar nenhum" - longe dos anelos da humanidade.

Neste contexto, convém ressaltar a dificuldade que alguns países teriam no sentido de enfrentar a equanimidade de ações contra as nações que colaboram com o desgoverno mundial, como é o caso, por exemplo, do privilégio de 5 (cinco) membros permanentes do Conselho de Segurança da ONU que possuem poder de veto quanto às intervenções no ambiente geopolítico que contrariam os direitos da dignidade humana. É o caso dos Estados Unidos, da Inglaterra, da França, da Rússia e da China, que certamente vetam qualquer possibilidade de sanção contra si mesmos. Certamente, dentro dessa linha de pensamento se enquadra a crítica de Pagliarini (in BERTOLDI; SPOSATO, 2011, p. 58), quando considera que "o reconhecimento da pessoa humana, pela ONU, como portador de personalidade internacional abriria flanco não só para a supressão de uma vetusta proibição, mas - o que é melhor - criaria ensejo para que se começasse a implantar a democracia da mais importante organização internacional do planeta, na ONU - que, até agora, só tem sido um instrumento de governantes e burocratas [grifo meu]".

Ou seja, que o verdadeiro efeito contra as ameaças em relação à dignidade humana também deveria controlar a ambição das superpotências que se consideram acima de quaisquer suspeitas.

\section{REFERÊNCIAS}

ANGHER, Anne Joyce (Org.). Vade Mecum acadêmico de Direito Rideel. 24. ed. São Paulo: Rideel, 2017.

BARELLI; PENNACHIETTI. Dicionário das citações. São Paulo: Martins fontes, 2001.

BARROSO, Luíz Roberto. A dignidade da pessoa humana no direito constitucional contemporâneo.

A Construção de um Conceito Jurídico à Luz da Jurisprudência Mundial. Tradução: Humberto

Laport de Mello. - 3. reimpressão. Belo Horizonte: Fórum, 2014.

BERTOLI, Márcia Rodrigues; SPOSATO, Karyna Batista. (Coordenadoras). Direitos Humanos: entre a utopia e a contemporaneidade. Belo Horizonte: Fórum, 2011.

BOBBIO, Norberto. Era dos Direitos. Tradução: Carlos Nelson Coutinho. Rio de janeiro: Elsevier, 2004.

COMPARATO, Fábio Konder. A Afirmação Histórica dos Direitos Humanos. 10. ed. São Paulo: Saraiva, 2015.

CURY, Augusto. Colecionador de lágrimas: Holocausto nunca mais. São Paulo: Planeta, 2012.

GUERRA FRIA, https://www.suapesquisa.com/guerrafria/, acessado em 29 de março de 2018. 
HÄBERLE, Peter. El Estado Constitucional. Trad. Hector Fix-Fierro, D.F.: Universidad Autônoma de México; 2001. Discurso proferido em 25.5.2009, na Embaixada da República Federativa da Alemanha por ocasião dos 60 anos da Lei fundamental de Bonn, disponível em [fonte: www.stf.jus. br.>anexo>discAlemnha, acessado em 28.03.2018].

MACHADO, Clara. Princípio Jurídico da Fraternidade: Um instrumento para a proteção de direitos fundamentais transindividuais. Rio de Janeiro: Lumen Juris, 2017.

MARKERT, Verner. Trabalho e consciência Mudanças na sociedade do trabalho e a reconstrução da teoria de classe. [disponível em fonte: http://www.scielo.br/pdf/ts/v14n2/v14n2a02.pdf, acessado em 15.03.2018]. Tempo Social; Ver. Sociol. USP, São Paulo, 14(2): 19-36, 2002.

MIRANDA, Jorge. A evolução dos direitos fundamentais até os tempos contemporâneos. In: BERTOLI, Márcia Rodrigues; SPOSATO, Karyna Batista (Coord.). Direitos Humanos: entre a utopia e a contemporaneidade. Belo Horizonte: Fórum, p. 83-89, 2011.

PACTO INTERNACIONAL SOBRE OS DIREITOS ECONÔMICOS, SOCIAIS E CULTURAIS, Disponível em http://www.unfpa.org.br/Arquivos/pacto_internacional.pdf., acessado em 9.05.2018. [1976].

PAGLIARINI, Alexandre Coutrinho. A contemporaneidade dos direitos humanos depende da eficácia do direito internacional. Utopia?. In: BERTOLI, Márcia Rodrigues; SPOSATO, Karyna Batista (Coord.). Direitos Humanos: entre a utopia e a contemporaneidade. Belo Horizonte: Fórum, 2011.

PIOVESAN, Flávia. Direitos humanos e justiça internacional. Um estudo comparativo dos sistemas regionais europeu, interamericano e africano. 7 ed. São Paulo: Saraiva, 2017.

SATO, Eiiti. Agenda Internacional depois da guerra fria: novos temas e novas percepções. Disponível em fonte: http://www.scielo.br/scielo.php?script=sci_arttext\&pid =S0034-73292000000100007, acessado em 15.03.2018]. Rev. bras. polít. int. vol.43 no.1, Brasília Jan./June, 2000.

ZIPPELIUS, Reinhold. Teoria Geral do Estado. Ciência Política. Tradutores: Antônio Francisco de Souza, Antônio Franco. São Paulo: Saraiva, 2016. 
1 Mestre em Ciência Jurídica pelo Programa de Pós-graduação da Universidade Estadual do Norte do Paraná, graduada em Direito pela Universidade Tiradentes, no Estado de Sergipe.samyle.adv@gmail.com

2 Professora do Programa de Pós-Graduação em Direito da UNIT/SE e do Programa de Pós-graduação em Sociedade, Tecnologias e Políticas Públicas do UNIT/AL. veronica_marques@set.edu.br

3 Graduando em Direito da Universidade Tiradentes. É licenciado em Filosofia pela Faculdade Batista Brasileira (FBB), com reconhecimento da Universidade Tiradentes (Unit), pós-graduado em Metodologia e Didática do Ensino Superior pela Faculdade São Luiz de França (FSLF). Mestrado em Teologia Bíblica pela Pontifícia Universidade Gregoriana (PUG), de Roma, sendo civilmente reconhecido pela Pontifícia Universidade Católica (PUC) do Rio de Janeiro.sotrolig@gmail.com

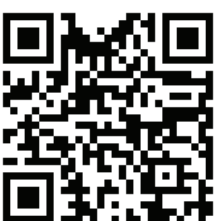

A autenticidade desse artigo pode ser conferida no site https://periodicos. set.edu.br

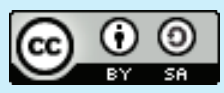

Este artigo é licenciado na modalidade acesso abertosob a Atribuição-Compartilhalgual CC BY-SA

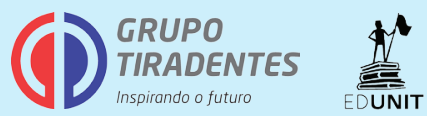


